\title{
Atypical Adenomatous Hyperplasia of the Lung: A Probable Forerunner in the Development of Adenocarcinoma of the Lung
}

Masuko Mori, M.D., Sudha K. Rao, M.D., Helmut H. Popper, M.D., Philip T. Cagle, M.D., Armando E. Fraire, M.D.

Department of Pathology (MM), Institute of Development, Aging and Cancer, Tohoku University, Sendai, Japan; Department of Pathology (SKR, AEF), University of Massachusetts Medical Center, Worcester, Massachusetts; Institute of Pathology (HHP), University of Graz, Graz, Austria; and Department of Pathology (PTC), Baylor College of Medicine, Houston, Texas

An increasingly large body of work suggests that atypical adenomatous hyperplasia (AAH) of the lung may be a forerunner of pulmonary adenocarcinoma. Recognizing this fact, the World Health Organization now acknowledges the existence of AAH while noting difficulties that may be encountered in distinguishing $A A H$ from the nonmucinous variant of bronchioloalveolar carcinoma. Regrettably, a universally acceptable definition of morphologic criteria for the diagnosis of AAH has not been achieved. This review of the literature examines the epidemiology, gross appearance, light microscopic findings, morphometry, immunohistochemistry, and molecular features of AAH and suggests a set of histopathologic features that may help the practicing pathologist identify this intriguing lesion. These features include the following: irregularly bordered focal proliferations of atypical cells spreading along the preexisting alveolar framework; prominent cuboidal to low columnar alveolar epithelial cells with variable degree of atypia but less than that seen in adenocarcinoma; increased cell size and nuclearcytoplasmic ratio with hyperchromasia and prominent nucleoli, generally intact intercellular attachment of atypical cells with occasional empty-looking spaces between them without high cellularity and without tufting or papillary structures; and slight thickening of the alveolar walls on which the AAH cells have spread, with some fibrosis but without scar formation or sig-

Copyright () 2001 by The United States and Canadian Academy of Pathology, Inc.

VOL. 14, NO. 2, P. 72, 2001 Printed in the U.S.A.

Date of acceptance: October 24, 2000.

Address reprint requests to: Armando E. Fraire, M.D., Department of Pathology, University of Massachusetts Medical Center, 55 Lake Avenue

North, Worcester, MA 01655; fax: 508-856-2968. nificant chronic inflammation of the surrounding lung tissue. Several lines of evidence indicate that AAH is a lesion closely associated with adenocarcinoma of the lung, suggesting AAH may be involved in the early stage of a complex multistep carcinogenesis of pulmonary adenocarcinoma.

KEY WORDS: Carcinogenesis, Lung cancer, Pulmonary adenocarcinoma, Preneoplastic lesion, Atypical adenomatous hyperplasia.

Mod Pathol 2001;14(2):72-84

Lung cancer is one of the most commonly diagnosed major cancers in the world. Among the major types of lung cancer, adenocarcinoma is rapidly emerging as a leading cell type in countries such as the United States and Japan $(1,2)$. Although several hypotheses have been proposed, the pathogenesis of adenocarcinoma remains largely unknown. This limited understanding of the pathogenesis of pulmonary adenocarcinoma is in contrast to that of squamous cell carcinoma of the lung, in which the course of development and the natural history are better understood (3-6). One problem in research of the pathogenesis of pulmonary adenocarcinoma is the difficulty in detecting or evaluating presumptive precursor lesions (7). This is probably partly because the location of most adenocarcinomas at the periphery of the lung, which limits detection and access to early lesions by means of flexible fiberoptic endoscopy and by means of cytology, biopsy, or both.

In earlier studies, the concept of "scar cancer" was implicated in the pathogenesis of pulmonary adenocarcinoma (8-14). The concept of scar cancer was based on the observation that most peripheral adenocarcinomas contain a central or subpleural anthracotic and fibrotic focus, which is often asso- 
ciated with an area of pleural puckering or retraction. Thus in these old fibrotic areas, presumptively produced by a previous bout of inflammation, the epithelia of small airways enclosed within the scar were considered to be particularly susceptible to malignant transformation. However, Shimosato et al. (15) have proposed an alternative explanation that the central fibrotic focus with anthracosis is formed after the development of carcinoma, probably as a result of alveolar wall collapse brought about by degeneration, and death of tumor cells lining along the alveoli in the early stage adenocarcinoma (16). Subsequently, fibroblastic cell proliferation and collagenization follow. Most authors currently subscribe to the latter pathogenetic mechanism. However, there remains a subset of true peripheral lung scar cancers, mostly adenocarcinomas, that appear to secondarily develop in previous fibrotic foci, particularly in patients from the parts of the United States where histoplasmosis is endemic (17).

Meyer and Liebow (18) focused on the occurrence of atypical proliferative foci of the lung in the setting of diffuse interstitial fibrosis, which were regarded as important premalignant lesions. These proliferative foci appear equivalent to what is called today atypical adenomatous hyperplasia (AAH). A plethora of synonyms has been used in the literature to refer to AAH. These include the following: atypical regenerative hyperplasia (19), atypical epithelial proliferation (18), atypical alveolar epithelial hyperplasia (20), atypical alveolar cuboidal cell hyperplasia $(15,21,22)$, atypical bronchioloalveolar cell hyperplasia $(23,24)$, alveolar atypical hyperplasia (25), and bronchioloalveolar cell adenoma (26). AAH is best regarded as a small proliferative lesion comprising single-layered atypical cells that resemble Clara cells or type II alveolar cells lining along the alveolar septa. Similar lesions may be observed not only as solitary foci in the nonneoplastic lung but also as foci in continuity with adenocarcinoma $(7,21,22,24,27,28)$. The cells comprising AAH show various degrees of atypia, such as nuclear hyperchromasia, enlargement, and pleomorphism, as well as prominent nucleoli, variable cellularity, and general architectural disarray.

A number of studies have suggested that the grade of atypia in AAH is milder than that of adenocarcinoma. However, a unified, widely accepted set of histopathologic criteria for diagnosis of AAH remains to be established. In fact, the histopathologic distinction between AAH with severe atypia and well-differentiated bronchioloalveolar carcinoma (BAC) can be very difficult on basis of histopathology alone, and in such cases, the diagnosis is usually made subjectively and in conjunction with the clinical and radiographic findings. Further, the biological nature of AAH is poorly understood and remains controversial, with some investigators regarding AAH as a precursor of $\operatorname{BAC}(7,24,29)$ and others regarding it as an adenoma or, conversely, as an extremely well differentiated BAC $(21,23,26-28$, $30,31)$.

This review aims to discuss the epidemiology and recent advances in the understanding of $\mathrm{AAH}$, which may help diagnostic pathologists to recognize AAH. This review further discusses studies that have used various ancillary methodologies such as morphometry, immunohistochemistry, cytogenetic methods, molecular analyses, and animal models.

\section{Epidemiology}

To our knowledge, population-based epidemiologic studies addressing the frequency of AAH have not been reported. There are, however, several studies that provide some insight on the frequency of AAH in hospital-based populations. Miller (26) examined 247 cases of surgically resected lung carcinomas by sectioning all areas of the lung transversely at $1.0-$ to $1.5-\mathrm{cm}$ intervals and found 23 (9.3\%) of lesions to be what she called bronchioloalveolar cell adenomas. Other investigators have reported a frequency of AAH of 5 to $20 \%$ in surgically resected lungs for pulmonary carcinoma $(20,32-$ 36). Weng et al. (32) reviewed the literature that examined the incidence of AAH and found that it was notably higher in specimens obtained from patients with primary lung carcinoma $(20.0 \%)$ than in those with nonprimary lung carcinoma (4.8\%). Among several histopathologic types of lung carcinoma, AAH has been found most frequently in resected lungs of patients with pulmonary adenocarcinoma, especially well differentiated papillary adenocarcinoma, and BAC $(20,32,34-36)$. Other researchers have reported that incidences of AAH in the range of 1.2 to $12 \%$ in surgically resected adenocarcinoma of the lung $(25,28,35,37)$.

Recently, we examined 100 consecutive general autopsy cases, excluding cases of primary and metastatic pulmonary neoplasia, and found two cases of AAH (38). However, as noted above, the true frequency of $\mathrm{AAH}$ in the general population remains unknown. According to Weng et al. (32), the incidence of AAH appears to be unrelated to sex. Weng et al. also reported that there is no definite correlation between smoking history and the occurrence of AAH. In contrast, Chapman and Kerr (36) have recently demonstrated that a greater percentage of women with adenocarcinoma had AAH $(30.2 \%)$ than did men with adenocarcinoma $(18.8 \%)$.

\section{Gross Pathologic Findings}

Little is known about the gross appearance of AAH. AAH has been reported to occur both as a 
poorly defined lesion occurring in continuity with a marginal area of pulmonary adenocarcinomas and also as a solitary lesion, unassociated with adenocarcinoma. Solitary AAHs are usually small, varying from less than $1 \mathrm{~mm}$ to $10 \mathrm{~mm}$ in maximum diameter, and are spatially distinguishable from the primary tumor or from areas of obstructive pneumonitis (Fig. 1) (2, 23, 25, 26, 32, 39, 40). Nakanishi (20) notes that peripheral AAH lesions may present as gray-white nodules occurring within $10 \mathrm{~mm}$ of the overlying pleura. On the other hand, Shimosato et al. (2) and Carey et al. (25) called attention to grossly recognizable alveolar lesions presenting as pale and poorly defined foci in the lung. AAH has been detected in random sections of normal lung parenchyma fixed in formalin. Miller, however, has suggested the use of Bouin's solution, which renders these lesions more apparent at gross inspection, as an alternative to the routinely used formalin fixatives $(23,26)$.

\section{Light Microscopic Findings}

Microscopically, AAHs may appear as focal proliferative lesions growing at the periphery of the lung $(25,37)$. The basic histopathologic finding of AAH is focal proliferation of alveolar cells spreading along the preexisting alveolar framework (Fig. 2) (2, $7,20-22,24,26,28,32-34)$. The cells that compose AAH are apt to be mildly to moderately atypical with increased nuclear-cytoplasmic ratio, often possessing hyperchromatic nuclei and prominent nucleoli. Rao and Fraire (22) noted that the size of cells found in AAH was at least double the size of neighboring normal cells. Mitotic figures are rarely seen in AAH $(2,28,33)$. AAH of mild to moderate atypia and $\mathrm{AAH}$ of severe atypia are illustrated in Figure $3(20,25,34,37)$.

The degree of nuclear atypia is milder than that seen in well-differentiated adenocarcinoma (Fig. 4) $(2,7,15,21,28)$. The cells of AAH are usually attached to each other, replacing the normal epithelium of several alveoli. Occasionally, empty spaces can be found between the atypical cells. The alveolar walls are slightly thickened with mild infiltration of inflammatory cells but without scar formation, whereas the lung tissue surrounding AAH is not accompanied by chronic inflammatory reaction in the interstitium. Miller (26) described the relationship between size of lesions and nuclear atypia with smaller lesions as tending to have milder nuclear atypia and larger lesions as tending to have greater degree of nuclear atypia. Most investigators appear to agree that a milder degree of cellular atypia and the absence of high cellularity, papillary structures, and stromal and vascular invasion are histopathologic features that help distinguish $\mathrm{AAH}$ from adenocarcinoma (Fig. 4).

In summary, our review of the literature and personal observations suggest that in terms of light microscopy, the following histologic features may
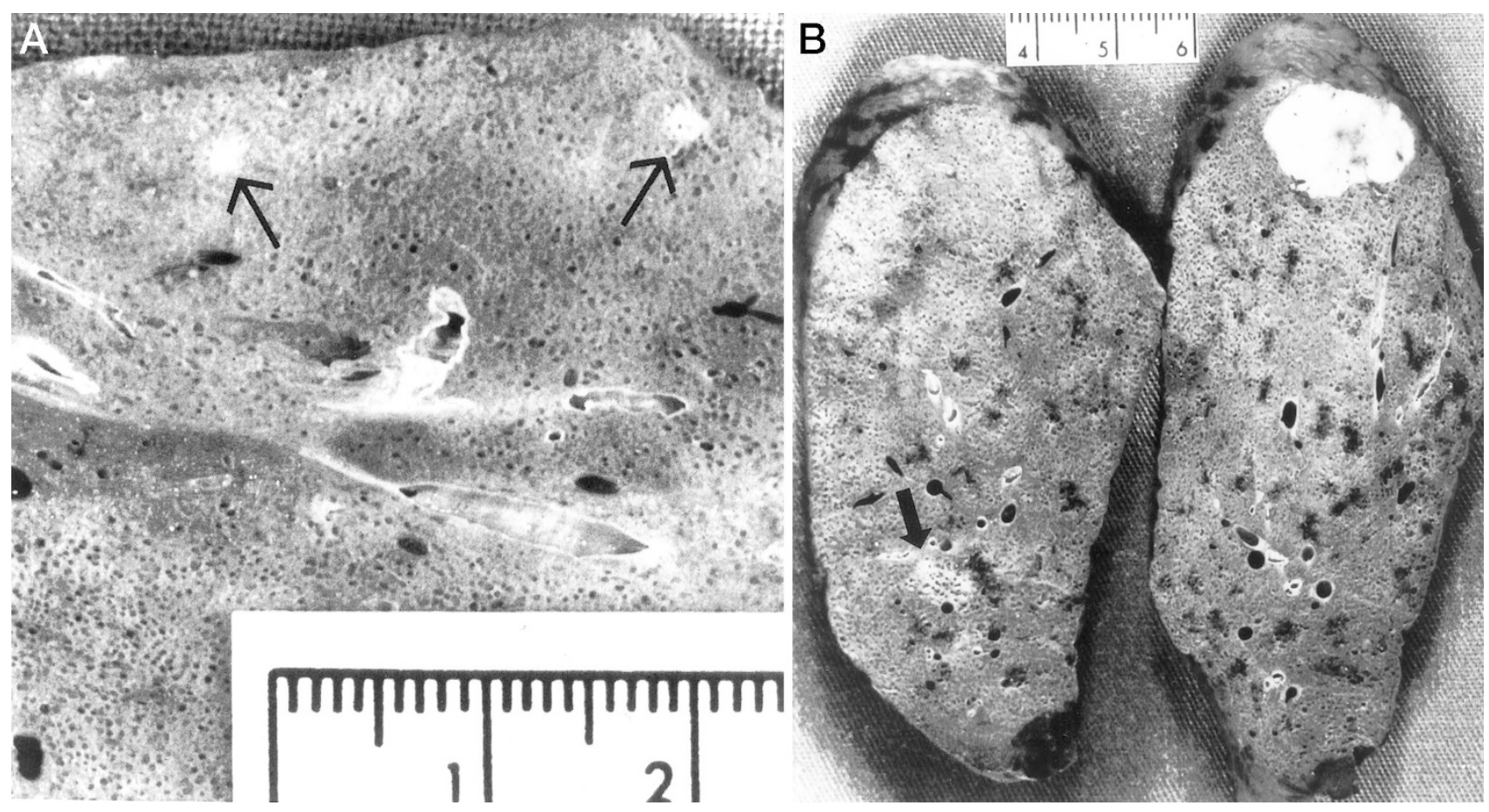

FIGURE 1. A, gross appearance of two nodular lesions representing bronchioloalveolar adenomas (atypical adenomatous hyperplasia), each 2 to 3 $\mathrm{mm}$ in diameter. Reproduced with permission from Miller (26). B, gross appearance of bronchioloalveolar adenoma (atypical adenomatous hyperplasia) about $6 \mathrm{~mm}$ in diameter (arrow). The lesion has a white, lacy appearance and a poorly defined outline. A large white primary tumor can also be seen (top right). Reproduced with permission from Miller (26). 
be of help in classifying atypical lesions as AAH and to distinguish them from well-differentiated adenocarcinoma: irregularly bordered focal proliferations of atypical cells spreading along the preexisting alveolar framework; prominent cuboidal to low columnar alveolar epithelial cells with generally mild but variable degree of atypia, less than that seen in

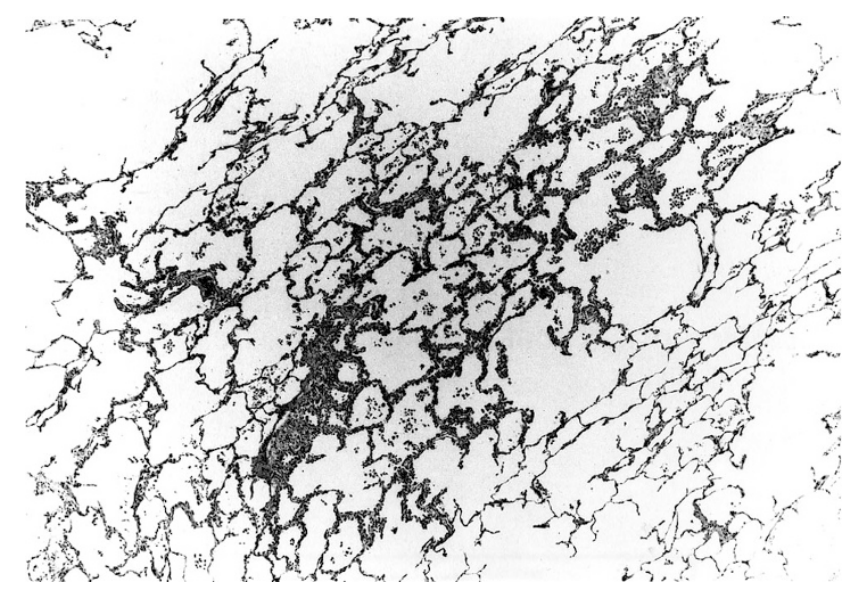

FIGURE. 2. Atypical adenomatous hyperplasia illustrating a focal proliferative epithelial lesion of the periphery of the lung. The growth pattern spreads along the preexisting alveolar framework. Hematoxylin and eosin; original magnification, $55 \times$. Reproduced with permission from Weng et al. (32). adenocarcinoma; increased cell size and nucleolicytoplasmic ratio with hyperchromasia and prominent nucleoli; generally intact intercellular attachment of atypical cells with occasional empty spaces between them without high cellularity and without tufting or papillary structures; and slight thickening of the alveolar septa on which the AAH cells have spread, with some fibrosis but without scar formation or significant chronic inflammation of the surrounding lung tissue.

\section{Morphometry}

Histopathologic differences between AAH with severe atypia and well-differentiated adenocarcinoma are often so subtle that reproducible diagnoses are not always possible, even in the hands of experienced pathologists. Therefore, efforts have been made to improve the accuracy of the diagnosis of AAH in a reproducible way. One such effort has used computer-assisted morphometry. Recent progress in morphometrical measurements has aided pathologists in the evaluation of cancerrelated lesions in a reproducible manner on the basis of quantitative measurements (41). Initial successful morphometrical analyses were applied to

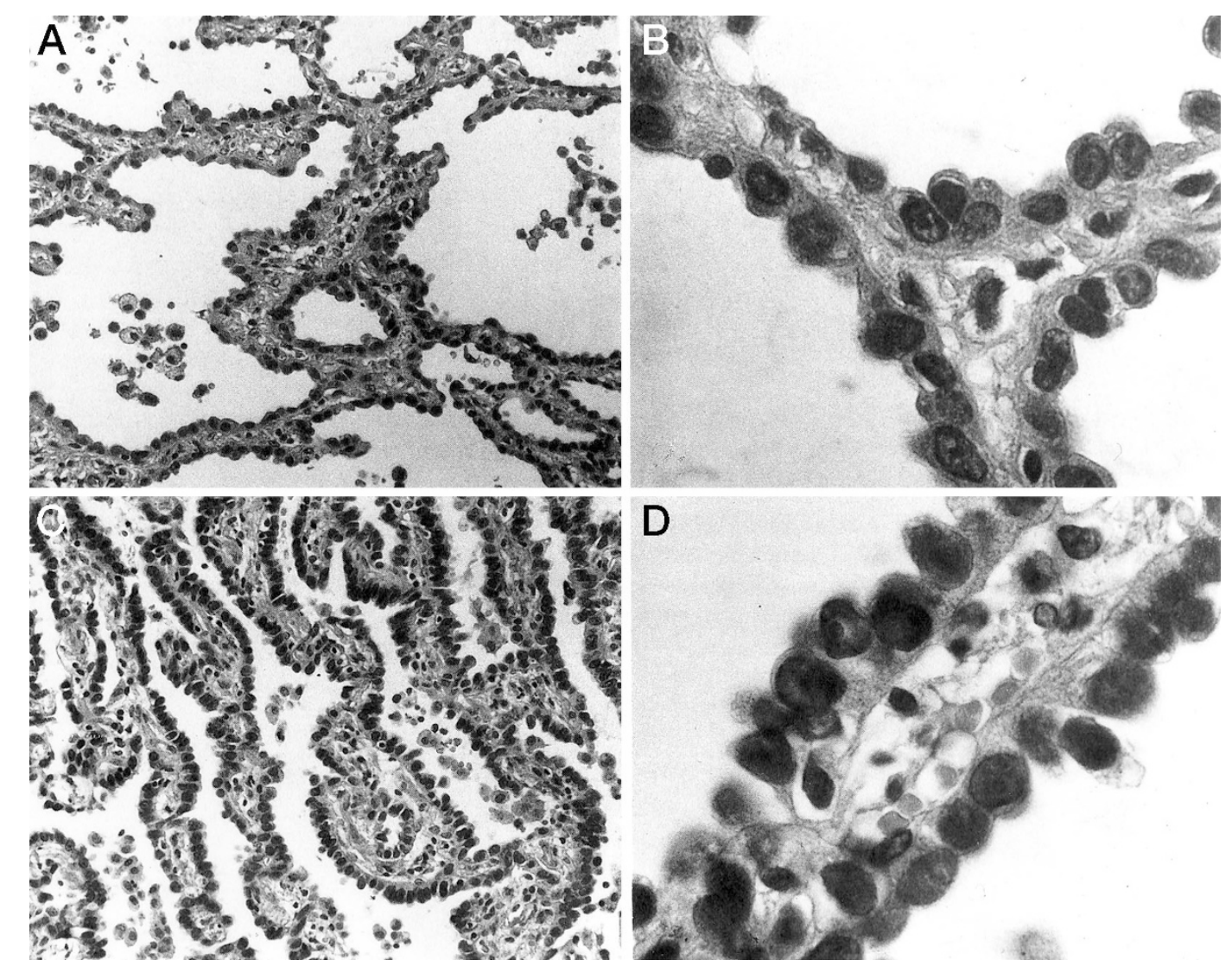

FIGURE 3. Atypical adenomatous hyperplasia (AAH) of varying degree of atypia. A and B, AAH of mild to moderate atypia; growth can be seen along the preexisting alveolar framework. $\mathbf{C}$ and $\mathbf{D}$, AAH of severe atypia. However, the degree of nuclear atypia is milder than that seen in welldifferentiated adenocarcinoma. Hematoxylin and eosin; original magnification, $66 \times($ A and C) and $330 \times($ B and D). Reproduced with permission from Mori et al. (7). 
hepatocellular carcinoma (42) and malignant lymphomas $(43,44)$ with the aim of distinguishing them from benign lesions by measuring mean nuclear size. Similar approaches have been found useful in evaluating the differences between low-grade and high-grade malignant tumors of the breast (45) and bladder cancers $(46,47)$, as well as some subtypes of malignant lymphoma (48).

Recently, morphometrical analyses have also been used to distinguish AAH from adenocarcinoma of the lung. Kodama et al. (21) calculated the mean nuclear area (MNA) and standard deviation of nuclear area morphometrically and demonstrated the usefulness of this approach in distinguishing AAH from adenocarcinoma (37), suggesting that some adenocarcinomas may derive from AAH. Nakanishi (20) also found highly significant differences between AAH and adenocarcinoma by use of morphometry of MNA and standard deviation of nuclear area. Kitamura et al. $(49,50)$ classified AAH into three morphometric categories on

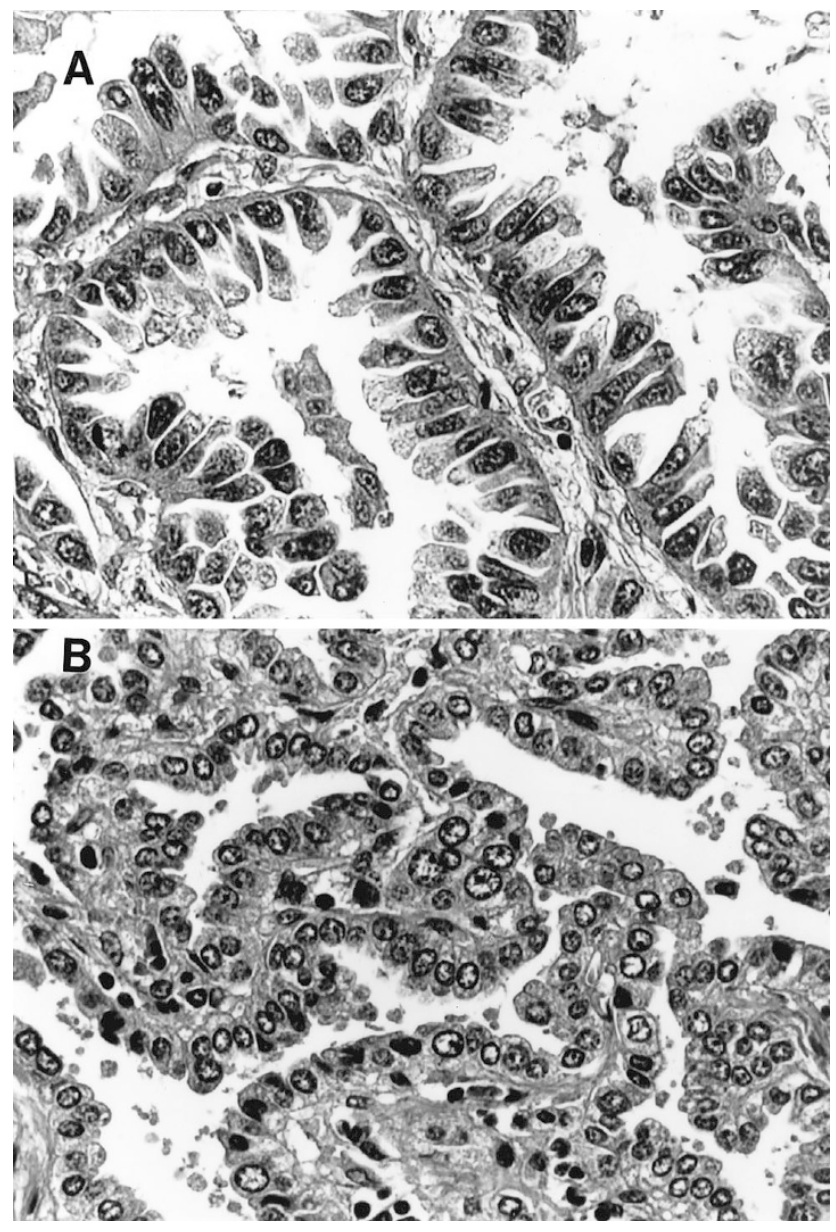

FIGURE 4. A, Clara cell type adenocarcinoma with cuboidal to low columnar cells, peg or club shaped, projecting into the lumina beyond the level of the lateral cell junction. B, type 2 pneumocyte type adenocarcinoma with cuboidal cells with round nuclei, dome-shaped free surface, and finely vesicular cytoplasm. Hematoxylin and eosin; original magnification, $132 \times$. Reproduced with permission from Mori et al. (54). the basis of the degree of cellular atypia, consisting of low-grade $\mathrm{AAH}$ as a benign lesion, high-grade $\mathrm{AAH}$ as a lesion of uncertain malignancy, and AAHlike carcinoma as a potentially malignant or borderline malignant lesion. They concluded that the morphometrical approach with MNA, coefficient of variation of nuclear area, and lesion size are useful in the distinction between AAH and early BAC. The cut-off values for the distinction of early BAC from AAH proposed in their study were $40 \mu \mathrm{m}^{2}$ for MNA and $5 \mathrm{~mm}$ for gross size of the lesion. They also demonstrated that distinction of lung lesions with any single parameter alone is not sufficient because of considerable overlap of each parameter caused by a continuous spectrum of neoplastic cellular changes that are expressed in AAH, early BAC, and overt BAC.

Therefore, further alternative modes to measure and quantitate cellular atypia have been proposed. One such attempt is multivariate cluster analysis. We recently applied multivariate cluster analysis in the evaluation of AAH by use of several parameters, such as means and variances of the size, shape, and position of the nucleus and the size and shape of the cell, to establish objective, reproducible microscopic criteria for AAH $(7,51)$. This study showed that AAH is definable by a combination of several parameters and found that some of the cases designated as AAH may actually contain elements of type II pneumocyte-type adenocarcinoma in their early stages. We concluded that borderline malignant lesions themselves can be part of the multistep process of carcinogenesis. Our findings in that study further suggested that AAH may be a lesion closely related to Clara cell type and type II pneumocyte-type adenocarcinomas, possibly as their common precursor.

\section{Immunohistochemical Characteristics}

The distribution of carcinoembryonic antigen (CEA) is known to vary with the degree of cellular atypia during the carcinogenic sequence of colorectal and pancreatic adenocarcinomas $(52,53)$. In regards to lung, Nakanishi (20) studied 27 lesions of typical and atypical alveolar epithelial hyperplasia in association with primary lung adenocarcinoma and found that atypical alveolar epithelial hyperplasia was positive for CEA more frequently than typical alveolar epithelial hyperplasia, a lesion that has been referred to as adenomatous hyperplasia $(\mathrm{AH})$, considered to be a nonneoplastic reactive change of bronchioloalveolar cells with no preneoplastic potential (Fig. 5). However, there were no significant differences between atypical alveolar epithelial hyperplasia and adenocarcinoma in regards to their expression of CEA. Carey et al. (25) studied 10 cases of AAH and found that many of the atypical 
lesions, unlike the surrounding lung parenchyma, expressed CEA, but not as strongly as adenocarcinomas. In a previous study, we evaluated CEA expression in more than 100 lesions consisting of Clara cell type and type 2 pneumocyte-type adenocarcinomas, $\mathrm{AAH}$ and $\mathrm{AH}$ as well as normal Clara cells and type 2 pneumocytes and reported that the CEA expression in AAH was comparable to that in adenocarcinomas (54). In contrast, there was an absence of expression of CEA in normal Clara cells, type 2 pneumocytes, and AH. This immunoreactivity to CEA and several other immunohistochemical markers is illustrated in Figure 6. The grading of immunoreactivity for CEA and the other markers is outlined in the previous study and will not be discussed here (54). Shimosato et al. (2) reported that CEA is not detected generally in AH but is found in AAH with increased cellular atypia and density. Rao and Fraire (22) found negative staining for CEA in the majority of AAH, whereas almost all adenocarcinomas showed a positive reaction.

$\mathrm{A}, \mathrm{B}$, and $\mathrm{H}$ blood group antigens are present in the plasma membranes of many different types of epithelial cells, and the loss of these antigenic specificities has been observed in various types of carcinomas. Nakanishi (20) demonstrated a decreased expression of blood group antigens in AAH but found no significant differences in the expression of these antigens between AAH and adenocarcinoma. Weng et al. (55) investigated the expression of the so-called secretory component in a case of multiple AAH associated with a BAC of the lung. They reported positive reactivity in AAH with mild to marked atypia and also in primary carcinoma of the lung.

We have reported that immunoreactivity of cytokeratin and laminin were helpful in discriminating AAH from bronchioloalveolar adenocarcinoma because invasion was highlighted or proven by the destruction of the basal lamina, outlined by a lami-

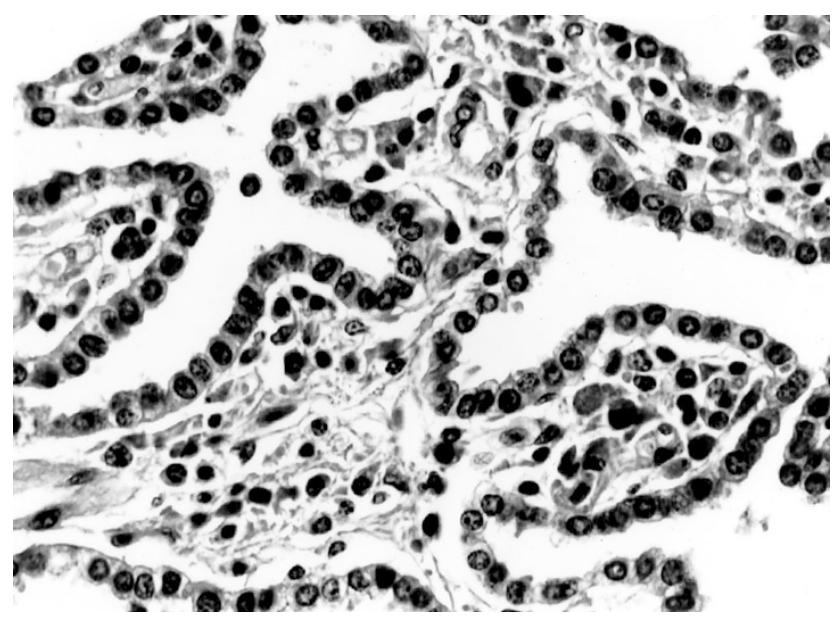

FIGURE 5. Adenomatous hyperplasia with cuboidal cells and round nuclei but without nuclear atypia. Hematoxylin and eosin; original magnification, $132 \times$. Reproduced with permission from Mori et al. (54). nin stain (56). Tumor cells were in addition clearly marked by the cytokeratin stain. We also investigated the expression of Leu-M1 and B72.3, which are regarded as markers of adenocarcinoma, and we reported limited expression of these markers in $\mathrm{AAH}$, whereas the majority of adenocarcinomas showed a positive reaction (22). We also reported high expression of CAM 5.2 and AE1/AE3, which are markers of epithelial differentiation in $\mathrm{AAH}$, and we found a similar degree of expression of these cytokeratins in both AAH and adenocarcinoma, with no significant differences between them (22). Moreover, we found an increased expression of CD74 and HLA-DR in AAH. We speculated that high expression of these molecules in AAH may allow elicitation of the immune response against atypical cells (57).

Carey et al. (25) demonstrated an increased rate of cell proliferation in AAH by use of an antibody (PC10) to proliferating cell nuclear antigen (PCNA) when comparing AAH with the adjacent unaffected lung parenchyma and found a much higher expression of PCNA in pulmonary adenocarcinomas, indicating possible dysregulation of the PCNA gene during development of pulmonary adenocarcinoma. Shimosato and associates (2) reported few PCNA-positive cells in AAH but noted an increased number of positive cells in areas with increased cell atypia and density. Kurasono et al. (58) evaluated the expression of cyclin D1, retinoblastoma gene protein, and p16 MTSI protein in AAH and adenocarcinoma. Overexpression of cyclin D1 was noted in AAH compared with adenocarcinoma and it was speculated that overexpression of cyclin D1 may be an early event that plays an important role in the tumorigenesis of lung adenocarcinoma. Kerr et al. (34) and Kitamura et al. (49) examined the expression of Ki 67 (MIB1) in AAH lesions and found that up to $10 \%$ of AAH cells expressed Ki 67 , in contrast to only a few normal alveolar epithelial cells and up to $50 \%$ of tumor cells in adenocarcinoma. Further, they found increased expression of $p 53$ and c-erbB-2 in AAH, concluding that AAH possesses some genetic changes that are associated with malignancy, and considered AAH as a premalignant lesion. Nakanishi et al. (59) have demonstrated an increase in silver staining argyrophilic nucleolar organizer regions in AAH, suggesting a status of increased cell growth activity in AAH. Martinez et al. (60) examined the expression of peptidyl-glycine a-amidating mono-oxygenase, an autocrine growth factor for lung tumors and tumor cell lines, in AAH next to pulmonary tumor. They demonstrated strongly positive expression of peptidyl-glycine a-amidating mono-oxygenase in AAH, suggesting involvement of peptide hormone stimulation of mitogenesis during the early phase of tumor progression. 
We also evaluated the expression of markers of differentiation toward Clara cells and type 2 pneumocytes, in Clara cell type and type 2 pneumocyte-type adenocarcinomas, AAH, AH, normal Clara cells, and normal type 2 pneumocyte cells by means of antibodies against surfactant apoprotein A, urine protein 1, and cytochrome P-450s (54). We found that AAHs expressed markers similarly to Clara cell type and type 2 pneumonocyte-type adenocarcinomas, and we concluded that AAH is a lesion closely related to Clara cell type and type 2 pneumocytetype adenocarcinomas, probably as a common precursor lesion for these two variants of adenocarcinoma (Fig. 6). Further ultrastructural studies demonstrating Clara-like, electron-dense granules and lamellar bodies in AAH (61) supported our hypothesis (62).

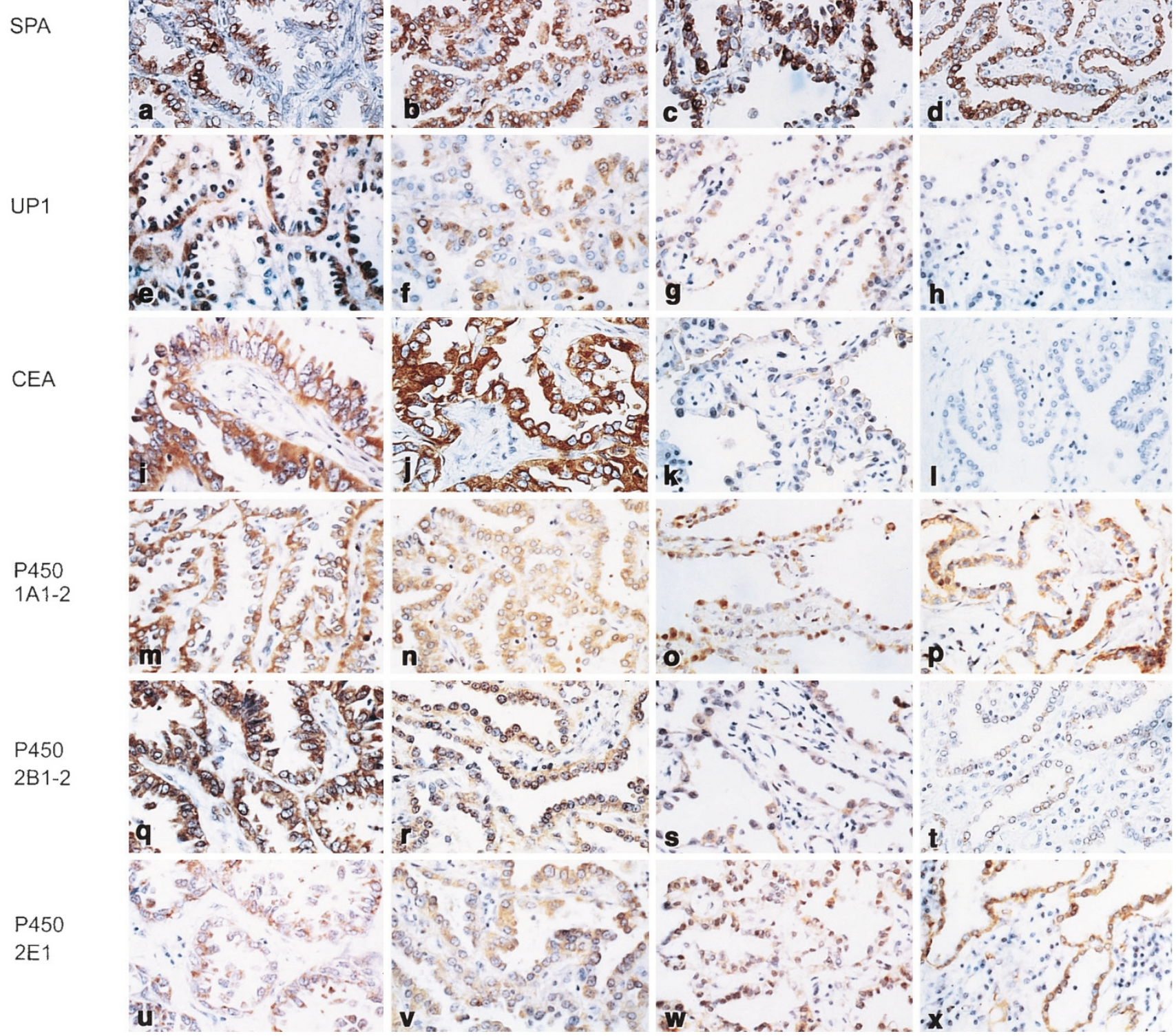

FIGURE 6. Immunohistochemistry of Clara cell type adenocarcinoma (a, e, i, m, q, u) type 2 pneumocyte type adenocarcinoma (b, f, j, $\mathbf{n}, \mathbf{r}, \mathbf{v})$ atypical adenomatous hyperplasia (AAH; c, g, k, o, s, w) and adenomatous hyperplasia (AH; d, h, l, p, t, x) (original magnification, 132×). Surfactant apoprotein A (SPA) immunohistochemistry is as follows: a, Grade 2; b, Grade 5; c, Grade 4; d, Grade 5. Urine protein 1 (UP1) immunohistochemistry is as follows: e, Grade 4; f, Grade 2; $\mathbf{g}$, Grade 4; h, Grade 0. Carcinoembryonic antigen (CEA) immunohistochemistry is as follows: i, Grade 3; j, Grade 3; k, Grade 2; l, Grade 0. Cytochrome P-450 1Al-2 immunohistochemistry is as follows: m, Grade 2; n, Grade 2; o, Grade 1 (nuclei were sometimes stained positively); p, Grade 2. Cytochrome P-450 2B1-2 immunohistochemistry is as follows: q, Grade 2; r, grade 2; s, Grade 2; t, Grade 1. Cytochrome P-450 2E1 immunohistochemistry is as follows: u, Grade 2; v, Grade 2; w, Grade 2 (nuclei were sometimes stained positively); $\mathbf{x}$, Grade 2. A semiquantitative scoring system is described in Mori et al. (54). Reproduced with permission from Mori et al. (54). 


\section{DNA Features}

Nuclear DNA content is regarded as a reliable indicator of malignancy in adenocarcinoma of the lung (2, 63-66). Analysis of the nuclear DNA content of AAH suggested clonal growth, with or without development of subclones, with more abnormal DNA content on the basis of the results obtained with cytofluorometric analysis of nuclear DNA content $(2,28)$. Niho et al. (67) demonstrated the monoclonality of AAH by means of clonal analysis on the basis of an $\mathrm{X}$-chromosome-linked polymorphic marker, the human androgen receptor gene. These authors suggested that AAHs, showing clonal proliferation, are more closely related to small-size, well-differentiated papillary adenocarcinoma. Yokozaki et al. (37) examined DNA histogram patterns of AAH lesions and found that $33 \%$ of $\mathrm{AAH}$ and $85 \%$ of adenocarcinomas had aneuploid histogram patterns. They suggested that some cases of AAH displaying aneuploid histogram patterns are precancerous lesions that may eventually progress to adenocarcinoma. Overall, these data support the hypothesis that AAH is a preneoplastic lesion and suggest that field effect may be important in the histogenesis of adenocarcinoma of the lung.

\section{Molecular Studies}

Series of independent studies have demonstrated that approximately 10 to 20 mutations are found in lung cancer tissue (68). Several lines of evidence indicate that mutations in K-ras and $p 53$ genes are the most frequent genetic changes in lung cancer. The K-ras gene encodes a membrane-associated guanine nucleotide-binding protein of approximately $21 \mathrm{kD}$ in size, designated p21-ras $(69,70)$. Activation of ras genes by mutations (71-73) may contribute to malignant transformation (74-77). Activating point mutations involving codon 12 of the K-ras oncogene are detected in 15 to $50 \%$ of all primary lung adenocarcinomas, whereas they are only rarely observed in other types of lung carcinomas (78-81). However, the timing of K-ras activation in lung tumorigenesis is unknown. Considering the uniform distribution of K-ras mutations in lung adenocarcinoma (19.5\%), Li et al. speculated that $\mathrm{K}$-ras activation occurs during the earliest stages of tumorigenesis preceding clinically evident tumor growth (82). Conversely, Sugio et al. (83) suggested that K-ras activation is a late event on the basis of the observation that mutations are rarely detected in preneoplastic epithelium adjacent to invasive lung carcinomas. Ohshima et al. (24) detected codon 12 point mutations of $\mathrm{K}$-ras oncogene by nested polymerase chain reaction amplification in $33.3 \%$ of AAHs with moderate to severe atypia and $20.7 \%$ of adenocarcinomas. They suggested that $\mathrm{AAH}$ in some cases is closely related to coexisting adenocarcinomas. They also found that there were mutation-positive and mutation-negative areas in the same patient, suggesting that mutation of K-ras gene occurred during the development of tumor. Westra and associates (84) also evaluated 41 AAHs and their paired lung neoplasms from 28 patients to detect codon 12 point mutations of $\mathrm{K}$-ras oncogene by polymerase chain reaction followed by allelespecific oligonucleotide hybridization. Mutations were found in 16 of 41 (39\%) AAHs, 8 of 18 (44\%) adenocarcinomas, and 1 of $5(0 \%)$ lung neoplasms that were not adenocarcinomas. These findings show that AAH possesses features more akin to adenocarcinoma, suggesting that glandular neoplasms of the lung arise from a background of field effect. Further, they also demonstrated that a significant proportion of AAH, like many lung adenocarcinomas, does not harbor codon $12 \mathrm{~K}$-ras mutations. Thus they concluded that lung tumorigenesis can progress through other genetic pathways not requiring activation of the K-ras oncogene. A more recent study that used transgenic models showed a role of v-Has-ras in the induction of multilineage pulmonary epithelial hyperplasia and neoplasia (85).

The protein product of the $p 53$ gene is thought to play an important role in the control of cell cycle, DNA repair, cell differentiation, and genomic plasticity (86). Abnormalities of the $p 53$ gene, predominantly missense mutations, lead to an impairment of the normal functions of the $p 53$ gene, resulting in neoplastic changes of the affected cells (86). Bodner et al. (87) reported that a high level of $p 53$ expression is correlated with missense mutations in exons 5 to 8 of the $p 53$ gene, which contain most of the evolutionarily conserved domains (86). p53 mutations lead to intranuclear accumulation of nonfunctional, stabilized p53 protein at levels high enough to allow detection by immunohistochemistry by use of anti-p-53 antibodies. However, special caution should be taken when interpreting results because nuclear accumulation of p53 protein can also be caused by stabilization of wild-type p53 protein through complex formation with several cellular and viral proteins $(86,88)$. On the other hand, in tumors with frame-shift or chainterminating mutations in the coding sequences of p53 gene, the levels of p53 protein are generally undetectable by immunohistochemical techniques (86).

p53 mutations have been reported in 24.4 to $53 \%$ of lung adenocarcinomas by several investigators $(34,50,82,89-92)$. Putative precursor lesions of lung carcinoma have also been evaluated in terms of p53 mutations. Accumulated evidence has shown that the precursor lesions of bronchial squamous cell carcinoma exhibit p53 abnormalities (up to $94 \%$ ) as early as the stage of intraepithelial dys- 
plasia and preinvasive carcinoma (93-97). Similarly, Li et al. (82) hypothesized that $p 53$ mutations in adenocarcinoma occur during the very earliest phase of tumor formation, before the bulk of clonal expansion, and occur in very small precursor lesions, based on finding demonstrating p53 mutations with a homogenous topographical distribution throughout the tumors.

The expression of p53 protein in AAH has also been evaluated by several researchers. Kerr et al. (34) reported that p53 protein was detected in $28 \%$ of AAH lesions with antibody DO7, whereas $53 \%$ of primary lung carcinomas showed positive staining of p53. Kitamura et al. (50) observed p53 expression in 5 to $8 \%$ of AAH lesions and 8 to $62 \%$ of BAC. On the contrary, most reactive epithelia show no p53 immunopositivity (or less commonly, immunopositivity) in only less than $10 \%$ of the cells (92). The frequency of p53 nuclear accumulation sequentially increases from low-grade AAH to high-grade AAH to AAH-like carcinoma, suggesting a continuous spectrum of neoplastic cellular changes (49, 50, $98,99)$. Discrepancies in the frequency of K-ras and p53 expression among these reports may be attributable to differences in staining procedures, including unmasking technique, evaluation of staining results, and criteria for classification of lung neoplasms, particularly AAH and early BAC. In spite of these differences, analysis of available data on K-ras and $p 53$ expression suggests that AAH exhibits some genetic changes associated with malignancy and thus supports the hypothesis that AAH is a premalignant lesion.

C-erbB-2 protein expression has been previously reported in up to $67 \%$ of adenocarcinomas of the lung $(34,100,101)$. In one study, $7 \%$ of AAH expressed membrane c-erbB-2 oncoprotein (34). All of these lesions had strongly positive p53 staining, and both p53 and c-erbB-2 staining were associated with increased cellularity and pleomorphism of $\mathrm{AAH}$. The authors speculated that AAH is premalignant and abnormal c-erbB-2 proto-oncogene expression may occur in the later carcinogenic sequence (34). In a more recent report, telomerase expression was assessed in preneoplasia of the lung (102). Telomerase positivity was detected in almost all lesions of metaplasia and dysplasia, whereas enzyme activity levels in these lesions were severalfold lower than those in the corresponding invasive lung tumors, suggesting the existence of telomerase dysregulation. In contrast, such dysregulation was often detected in lung adenocarcinoma but not in alveolar epithelial cells or AAH lesions (102). Thus telomerase activation seems to occur later in the carcinogenesis of adenocarcinoma, as compared with that of squamous cell carcinoma of lung. Altogether, these findings, obtained from multiple molecular analyses, strongly support the notion that AAH plays an important role in the development of pulmonary adenocarcinoma.

\section{Animal Models}

To date, no spontaneously occurring AAHbearing animal models appear to have been established. However, benign and malignant lung neoplastic lesions have been reported in some animal species. Tumors resembling BAC occur in the Fischer 344 rat. These may be difficult to be distinguished from adenomas. Stratification of neoplastic epithelium, solid areas of growth, cellular pleomorphism, and a schirrous reaction have been proposed as indicators of malignancy $(103,104)$.

A disease in sheep known as jaagsiekte (ovine pulmonary adenomatosis), an Afrikaans term meaning "the driving sickness," was first noticed among flocks driven from one pasturage to another; the affected animals became increasingly dyspneic, were forced to drop out of the flock, and eventually died (105). A similar disease, known as chronic progressive pneumonia of sheep, has been reported in Montana (105). Jaagsietke has also been reported in sheep, lambs, and goats from the Andean region of Peru $(105,106)$ and in sheep in Bulgaria $(105,107)$. In the lung of sheep suffering from jaagsiekte, neoplastic cuboidal epithelial cells growing in an acinar or papillary pattern may produce multifocal nodules. Extrathoracic and intrathoracic metastases are also frequently observed. Electron microscopy has revealed that neoplastic cells have some characteristics of alveolar type 2 pneumocyte and nonciliated bronchiolar epithelium, suggesting that neoplastic cells are derived from these epithelial cells $(108,109)$. Several experiments have suggested that viral infection may play a role in the etiology of lung tumors observed in jaagsiekte $(110,111)$. However, a precursor lesion of these neoplasms has not been well characterized. Thus the establishment of AAH-bearing animal models is highly desirable and would be of great help to analyze the natural evolution of $\mathrm{AAH}$, providing valuable information on the carcinogenesis of adenocarcinoma of the lung.

\section{SUMMARY}

Adenocarcinoma is now the predominant histologic type of lung cancer in Japan and some Western countries $(1,2)$. Clearly an understanding of possible precursor lesions for this increasingly frequent lung cancer would help establish a diagnostic classification as well as management strategies. An increasingly voluminous body of work suggests that AAH may be a precursor lesion of adenocarcinoma. Recognizing this fact, the World Health Organization now acknowledges the existence of AAH as a preinvasive lesion while noting difficulties that may 
be encountered in separating AAH from the nonmucinous variant of bronchioalveolar carcinomas (112). The World Health Organization further defines AAH as a "focal lesion, often $5 \mathrm{~mm}$ or less in diameter, in which the involved alveoli and respiratory bronchioles are lined by monotonous, slightly atypical cuboidal to low columnar epithelial cells with dense nuclear chromation, prominent nucleoli and scant cytoplasm" (112, p. 4).

A considerable body of knowledge has accumulated pertaining to the histopathology and other means of AAH assessment, such as morphometry, immunohistochemistry, and molecular studies. Regrettably, morphometric and molecular analyses and some complex immunohistochemical studies are not always available to many practicing pathologists. Thus in the foreseeable future, the diagnosis of AAH will likely continue to rest on arbitrary and subjective histologic criteria. On the basis of our review of the literature and our personal experience, we propose the following guidelines for the diagnosis of AAH: irregularly bordered focal proliferations of atypical cells spreading along the preexisting alveolar framework; prominent cuboidal to low columnar alveolar epithelial cells with variable degrees of atypia, less than that seen in adenocarcinoma; increased cell size and nuclear-cytoplasmic ratio with hyperchromasia and prominent nucleoli; intercellular attachment of atypical cells generally intact with occasional existence of empty-looking spaces between them without high cellularity and without tufting or papillary structures; and a slight thickening of the alveolar walls on which the AAH cells have spread, with some fibrosis but without scar formation or significant chronic inflammation of the surrounding lung tissue.

In regards to the possible precursor nature of $\mathrm{AAH}$, several lines of evidence, as discussed above, do suggest that AAH may play a role in the development of pulmonary adenocarcinoma and particularly in the development of BACs. However, we think that the putative precursor lesion of any cancer should fulfill some requirements (38). First, it should be present and identified before the development of the disease. Second, the precursor lesion should show evidence of cellular atypia, molecular changes, or both, consistent with progressive cellular transformation. Third, the precursor lesion should not occur so infrequently that transformation to neoplasia is a rare event (38). The data examined in this review only partly fulfills these requirements. We conclude, therefore, that $\mathrm{AAH}$ is a probable but not proven precursor lesion of pulmonary adenocarcinoma.

Last, practicing pathologists confronted with the possible significance of AAH must communicate with clinicians to ascertain prognosis and management of this lesion and with radiologists, who continue to enhance the resolution power of computed tomography and allied technologies that allow them to detect ever higher numbers of increasingly smaller pulmonary nodules (113). In regards to management, a conservative approach has been suggested by Colby et al. (114) and Ritter (115). This conservative approach suggests that small lesions found incidentally, without a gross correlate, that lack overwhelming features of malignancy, can be safely designated as AAH. Conversely, lesions that represent clinically or grossly observed lesions with compelling atypical features can be designated as malignant. Although many of the foregoing studies provide important information on the biology of AAH, much more work remains to be done with regard to the need to establish widely acceptable histopathologic criteria for the diagnosis of AAH. Large-scale, multi-institutional prospective studies and population-based studies linking molecular diagnostics to epidemiologic assessment of disease patterns and frequencies, as well as the development of appropriate experimental animal models, coupled with archives of morphologically and genetically studied cases at centralized Web sites, may provide additional insight and should help clarify the intriguing but as yet undefined role of AAH in the development of pulmonary adenocarcinoma.

Acknowledgment: The authors thank Karen Balcius for her help with the preparation of the manuscript.

\section{REFERENCES}

1. Travis WD, Lubin J, Ries L, Devesa S. United States lung carcinoma incidence trends: declining for most histologic types among males, increasing among females. Cancer 1996;77:2464-70.

2. Shimosato Y, Noguchi M, Matsuno Y. Adenocarcinoma of the lung: its development and malignant progression. Lung Cancer 1993;9:99-108.

3. Auerbach O, Gere JB, Pawlowski JM, Muehsam GE, Smolin HJ, Stout AP. Carcinoma-in-situ and early invasive carcinoma occurring in the tracheobronchial tree in cases of bronchial carcinoma. J Thorac Surg 1957;34:298-309.

4. Saccomanno G, Archer VE, Auerbach O, Saunders RP, Brennan LM. Development of carcinoma of the lung as reflected in exfoliated cells. Cancer 1974;33:256-70.

5. Carter D. Pathology of early squamous cell carcinoma of the lung. Pathol Annu 1978;14:131-47.

6. Mason MK, Jordan JW. Carcinoma in situ and early invasive carcinoma of the bronchus. Thorax 1969;24:461-71.

7. Mori M, Chiba R, Takahashi T. Atypical adenomatous hyperplasia of the lung and its differentiation from adenocarcinoma. Characterization of atypical cells by morphometry and multivariate cluster analysis. Cancer 1993;72:2331-40.

8. Friedrich G. Periphere lungenkrebse auf dem buden pleuranaher narben. Virchows Arch Pathol Anat 1939;304:23047.

9. Rossle R. Die Narbenkrebsge der lungen. Schweiz Med Wochenschr 1943;73:1200-3.

10. Raeburn C, Spencer H. A study of the origin and development of lung cancer. Thorax 1953;8:1-10.

11. Yokoo H, Suckow EE. Peripheral lung cancers arising in scars. Cancer 1961;14:1205-15. 
12. Kitagawa M. Autopsy study of lung cancer with special reference to scar cancer. Acta Pathol Jpn 1965;15:199-12.

13. Spencer H. Lung scar cancer. In: Shimosato Y, Melamed MR, Nettesheim P. editors. Morphogenesis of lung cancer. Vol 1. Boca Raton, FL: CRC Press; 1982. p. 111-20.

14. Madri JA, Carter D. Scar cancers of the lung: origin and significance. Hum Pathol 1984;15:625-31.

15. Shimosato Y, Kodama T, Kameya Y. Morphogenesis of peripheral type adenocarcinoma of the lung. In: Shimosato Y, Melamed MR, Nettesheim P, editors. Morphogenesis of lung cancer wall. Vol 1. Boca Raton, FL: CRC Press; 1982. p. 65-89.

16. Cagle PT, Cohle SD, Greenberg SD. Natural history of pulmonary scar cancers, clinical and pathologic implications. Cancer 1985;56:2031-5.

17. Yoneda K. Scar carcinoma of the lung in a histoplasmosis endemic area. Cancer 1990;65:164-8.

18. Meyer EC, Liebow AA. A relationship of interstitial pneumonia, honeycombing and atypical epithelial proliferation to cancer of the lung. Cancer 1965;18:322-51.

19. Friedländer C. Experimentaluntersuchnugen über chronishe pneumonie und lungenschwindsucht. Virchows Arch Pathol Anat 1876:68:325-63.

20. Nakanishi K. Alveolar epithelial hyperplasia and adenocarcinoma of the lung. Arch Pathol Lab Med 1990;114:363-8.

21. Kodama T, Biyajima S, Watanabe S, Shimosato Y. Morphometric study of adenocarcinomas and hyperplastic epithelial lesions in the peripheral lung. Am J Clin Pathol 1986; 85:146-51.

22. Rao SK, Fraire AE. Alveolar cell hyperplasia in association with adenocarcinoma of lung. Mod Pathol 1995;8:165-9.

23. Miller RR, Nelems B, Evans KG, Muller NL, Ostrow DN. Glandular neoplasia of the lung. A proposed analogy to colonic tumors. Cancer 1988;61:1009-14.

24. Ohshima S, Shimizu Y, Takahama M. Detection of $c$-ki-ras gene mutation in paraffin sections of adenocarcinoma and atypical bronchioloalveolar cell hyperplasia of human lung. Virchow Arch 1994;424:129-34.

25. Carey FA, Wallace WAH, Fergusson RJ, Kerr KM, Lamb D. Alveolar atypical hyperplasia in association with primary pulmonary adenocarcinoma: a clinicopathological study of 10 cases. Thorax 1992;47:1041-3.

26. Miller RR. Bronchioloalveolar cell adenomas. Am J Surg Pathol 1990;14:904-12.

27. Morinaga S, Shimosato Y. Pathology of minute adenocarcinoma in the peripheral lung. Pathol Clin Med Jpn 1987; 5:74-80.

28. Nakayama H, Noguchi M, Tsuchiya R, Kodama T, Shimosato Y. Clonal growth of atypical adenomatous hyperplasia of the lung: cytofluorometric analysis of nuclear DNA content. Mod Pathol 1990;3:314-20.

29. Mori M, Rao SK, Woda BA, Savas L, Baker SP, Fraire AE. Expression of bcl-2 oncoprotein in atypical adenomatous hyperplasia of the lung. In press.

30. Shimosato Y, Kodama T. Low grade malignant and benign tumors. Current problems. In: McDowell EM, editor. Tumor pathology: lung carcinomas. Edinburgh: Churchill Livingstone; 1987. p. 310-29.

31. Kitamura H, Kameda Y, Ito T, Hayashi H. Atypical adenomatous hyperplasia of the lung: implications for the pathogenesis of peripheral lung adenocarcinoma. Am J Clin Pathol 1999;111:610-22.

32. Weng SY, Tsuchiya E, Kasuga T, Sugano H. Incidence of atypical bronchioalveolar cell hyperplasia of the lung: relation to histological subtypes of lung cancer. Virchows Arch Pathol Anat 1992;420:463-71.

33. Noguchi M, Shimosato Y. The development and progression of adenocarcinoma of the lung. In: Hansen H, editor.
Lung cancer. Hingham, MA: Kluwer Academic Publishers; 1994. p. 131-42.

34. Kerr KM, Carey FA, King G, Lamb D. Atypical adenomatous hyperplasia: relationship with pulmonary adenocarcinoma, p53, and c-erB-2 expression. J Pathol 1994;174:249-56.

35. Susuki K, Nagi K, Yoshida J, Yokose T, Kodama T, Takahashi $\mathrm{K}$, et al. The prognosis of resected lung carcinoma associated with atypical adenomatous hyperplasia. Cancer 1997; 79:1521-6.

36. Chapman $\mathrm{AD}$, Kerr KM. The association between atypical adenomatous hyperplasia and primary lung cancer. Br J Cancer 2000;83:632-6.

37. Yokozaki M, Kodama T, Yokoge T, Matsumoto T, Mukai K. Differentiation of atypical adenomatous hyperplasia and adenocarcinoma of the lung by use of DNA ploidy and morphometric analysis. Mod Pathol 1996;9:1156-64.

38. Sterner DJ, Mori M, Roggli VL, Fraire AE. Prevalence of pulmonary atypical alveolar cell hyperplasia in an autopsy population: a study of 100 cases. Mod Pathol 1997;10:46973.

39. Shimosato Y, Noguchi M, Matsuno Y, Yamada T. Adenomacarcinoma sequence in non-mucus producing bronchioloalveolar carcinoma of the lung. Lung Cancer 1994;11: 98-9.

40. Suzuki K, Takahashi K, Yoshida J, Nishimura M, Yokose T, Nishiwaki Y, et al. Synchronous double primary lung carcinomas associated with multiple atypical adenomatous hyperplasia. Lung Cancer 1998;19:131-9.

41. Round JM, Jones DA, Edward RHT. A flexible microprocessor system for the measurement of cell size. J Clin Pathol 1982;35:620-4.

42. Jagoe R, Sowter C, Dandy S, Slavin G. Morphometric study of liver cell nuclei in hepatomas using an interactive computer technique: (1) nuclear size and shape. J Clin Pathol 1982;35:1057-62.

43. Crocker J, Jones EL, Curran RC. A quantitative study of the size of benign and malignant lymphoid follicles. J Clin Pathol 1983;36:1055-61.

44. Crocker J, Jones EL, Curran RC. Study of nuclear sizes in the centers of malignant and benign lymphoid follicles. J Clin Pathol 1983;36:1332-4.

45. Maehle BO, Thoresen S, Skjaerven R, Hartveit F. Mean nuclear area and histological grade of axillary node tumour in breast cancer, related to prognosis. Br J Cancer 1982;46: 95-100.

46. Ooms ECM, Anderson WAD, Alones CL, Boon ME, Veldhuizen RW. Analysis of the performance of pathologists in the grading of bladder tumors. Hum Pathol 1983;14:140-3.

47. Ooms ECM, Kurver PHJ, Veldhuizen RW, Alones CL, Boon ME. Morphometric grading of bladder tumors in comparison with histologic grading by pathologists. Hum Pathol 1983;14:144-50.

48. Crocker J, Jones EL, Curran RC. Study of nuclear diameters in non-Hodgkin's lymphomas. J Clin Pathol 1982;35:954-8.

49. Kitamura H, Kameda Y, Nakamura N, Nakatani Y, Inayama Y, Ida M, et al. Proliferative potential and p53 overexpression in precursor and early stage lesions of bronchioloalveolar lung carcinoma. Am J Pathol 1995;146:876-87.

50. Kitamura H, Kameda Y, Nakamura N, Inayama Y, Nakatani Y, Shibagaki T, et al. Atypical adenomatous hyperplasia and bronchoalveolar lung carcinoma: analysis by morphometry and the expressions of p53 and carcinoembryonic antigen. Am J Surg Pathol 1996;20:553-62.

51. Takahashi T, Chiba R, Mori M, Furukawa T, Suzuki M, Tezuka F. Computer-assisted pathology of intraepithelial adenocarcinoma and related lesions: 3-D distribution, structural aberration and discrimination. J Cell Biochem 1995;23:25-32. 
52. Hamada Y, Yamamura M, Hioki K, Yamamoto M, Nagura H, Watanabe K. Immunohistochemical study of carcinoembryonic antigen in patients with colorectal cancer: correlation with plasma carcinoembryonic antigen levels. Cancer 1985; 55:136-41.

53. Furukawa T, Chiba R, Kobari M, Matsuno S, Nagura H, Takahashi T. Varying grades of epithelial atypia in the pancreatic ducts of humans: classification based on morphometry and multivariate analysis and correlated with positive reactions of carcinoembryonic antigen. Arch Pathol Lab Med 1994;118:227-34.

54. Mori M, Tezuka F, Chiba R, Funae Y, Watanabe M, Nukiwa $\mathrm{T}$, et al. Atypical adenomatous hyperplasia and adenocarcinoma of the human lung. Their heterology in form and analogy in immunohistochemical characteristics. Cancer 1996;77:665-74.

55. Weng S, Tsuchiya E, Satoh Y, Kitagawa T, Nakagawa K, Sugano H. Multiple atypical adenomatous hyperplasia of type II pneumocytes and bronchiolo-alveolar carcinoma. Histopathology 1990;16:101-3.

56. Gollowitsch F, Pailer S, Popper HH. Atypical pneumocyte hyperplasia a probable precursor lesion of bronchioloalveolar adenocarcinoma of the lung [abstract]. Eur Respir J 1994; 7:135S.

57. Rao SK, Woda BA, Savas LM, Fraire AE. Expression of CD74 and class II major histocompatibility complex antigen (HLADR) in non small cell lung cancers (NSCLC) and associated alveolar cell hyperplasia. In press.

58. Kurasono Y, Ito T, Kameda Y, Nakaura N, Kitemura H. Expression of cyclin D1 retinoblastoma gene protein and p16 MTS1 protein in atypical adenomatous hyperplasia and adenocarcinoma of the lung. Virchows Arch 1998;432:207-15.

59. Nakanishi K, Hiroi S, Kawai T, Suzuki M, Torikata C. Argyrophilic nucleolar organizer region counts and DNA status in bronchioloalveolar epithelial hyperplasia and adenocarcinoma of the lung. Hum Pathol 1998;29:235-9.

60. Martinez A, Treston AM, Saldise L, Montuenga LM, Linnoila RI. Expression of peptidyl-glycine a-amidating monooxygenase (PAM) enzymes in morphological abnormalities adjacent to pulmonary tumors. Am J Pathol 1996;149:707-16.

61. Kitamura H, Kameda Y, Ito T, Hayashi H, Nakaumura N, Nakatani Y, et al. Cytodifferentiation of atypical adenomatous hyperplasia and bronchioloalveolar lung carcinoma. Immunohistochemical and ultrastructural studies. Virchows Arch 1997;431:415-24.

62. Mori M, Kaji M, Tezuka F, Takahashi T. Comparative ultrastructural study of atypical adenomatous hyperplasia and adenocarcinoma of the human lung. Ultrastruct Pathol 1998; 22:459-66.

63. Asamura H, Nakajima T, Mukai K, Noguchi M, Shimosato Y. DNA cytofluorometric and nuclear morphometric analyses of lung adenocarcinoma. Cancer 1989;64:1657-64.

64. Asamura H, Nakajima T, Mukai K, Shimosato Y. Nuclear DNA content by cytofluorometry of stage I adenocarcinoma of the lung in relation to postoperative recurrence. Chest 1989;96:312-8.

65. Nomori H, Hirohashi S, Noguchi M, Matsuno Y, Shimosato Y. Tumor cell heterogeneity and subpopulations with metastatic ability in differentiated adenocarcinoma of the lung. Histologic and cytofluorometric DNA analyses. Chest 1991; 99:934-40.

66. Nomori $H$, Nakajima T, Noguchi M, Iga R, Shimosato Y. Cytofluorometric analysis of metastases from lung adenocarcinoma with special reference to the difference between hematogenous and lymphatic metastases. Cancer 1991;67: 2941-7.

67. Niho S, Yokose T, Suzuki K, Kodama T, Nishiwaki Y, Mukai K. Monoclonality of atypical adenomatous hyperplasia of the lung. Am J Pathol 1999;154:249-54.
68. Idhe DC, Minna JD. Non-small cell lung cancer. Part I: biology, diagnosis, and staging. Curr Probl Cancer 1991;15: 65-147.

69. Chang EH, Gonda MA, Ellis RW, Scolnick EM, Lowy DR. Human genome contains four genes homologous to transforming genes of Harvey and Kirsten murine sarcoma viruses. Proc Natl Acad Sci U S A 1982;79:4848-52.

70. McCormick F. Ras GTPase activating protein: signal transmitter and signal terminator. Cell 1989;56:5-8.

71. Shih C, Weinberg RA. Isolation of transforming sequence from a human bladder carcinoma cell line. Cell 1982;29: 161-9.

72. Cooper GM. Cellular transforming genes. Science 1982;217: 801-6.

73. Pulciani S, Santos E, Lauver AV, Long LK, Aaronson SA, Barbacid M. Oncogenes in solid human tumors. Nature 1982;300:539-42.

74. Chang EH, Furth ME, Scolnick EML. Tumorigenic transformation of mammalian cells induced by a normal human gene homologous to the oncogene of Harvey sarcoma virus. Nature 1982;297:479-83.

75. Slamon DJ, deKernion JB, Verma IM. Expression of cellular oncogenes in human malignancies. Science 1984;224:25662.

76. Nowell PC. Biology of disease, cancer, chromosomes and genes. Lab Invest 1992;66:407-17.

77. Thor A, Ohuchi N, Hand PH, Callahan R, Weeks MO, Theillet C, et al. ras gene alterations and enhanced levels of ras p21 expression in a spectrum of benign and malignant human mammary tissues. Lab Invest 1986;55:603-16.

78. Rosenhuis S, Slebos RJC, Boot AJM, Evers SG, Moui WJ, Wagenaar SS, et al. Incidence and possible significance of $\mathrm{K}$-ras oncogene activation in adenocarcinoma of the human lung. Cancer Res 1988;48:5738-41.

79. Mills N, Fishman C, Rom W, Dubin N, Jacobson DR. Increased prevalence of K-ras oncogene mutations in lung adenocarcinoma. Cancer Res 1995;55:1444-7.

80. Slebos RJC, Kibbelaar RE, Dalesio O, Kooistra A, Stam J, Meijer CJLM, et al. K-ras oncogene activation as a prognostic marker in adenocarcinoma of the lung. N Engl J Med 1990; 323:561-5.

81. Kobayashi T, Tsuda H, Noguchi M, Hirohashi S, Shimosato $\mathrm{Y}$, Goya T, et al. Association of point mutation in c-Ki-ras oncogene in lung adenocarcinoma with particular reference to cytologic subtypes. Cancer 1990;66:289-94.

82. Li Z-H, Zheng J, Weiss LM, Shibata D. c-K-ras and p53 mutations occur very early in adenocarcinoma of the lung. Am J Pathol 1994;144:303-9.

83. Sugio K, Kishimoto Y, Virmani AK, Hung JY, Grazdar AF. $\mathrm{K}$-ras mutations are a relatively late event in the pathogenesis of lung carcinomas. Cancer Res 1994;54:5811-5.

84. Westra WH, Baas IO, Hruban RH, Askin FB, Wilson K, Offerhaus JA, et al. K-ras oncogene activation in atypical alveolar hyperplasias of the human lung. Cancer Res 1996;56:2224-8.

85. Sunday ME, Haley KJ, Sikorski K, Grapham SA, Emanuel RL, Zhang F, et al. Calcitonin driven v-Ha-ras induces multilineage pulmonary epithelial hyperplasias and neoplasms. Oncogene 1999;18:4336-47.

86. Harris CC, Hollstein M. Clinical implications of the p53 tumor-suppressor gene. N Engl J Med 1993;329:1318-27.

87. Bodner SM, Minna JD, Jensen SM, D’Amico D, Carbone D, Mitsudoni T, et al. Expression of mutant p53 proteins in lung cancer correlates with the class of p53 gene mutation. Oncogene 1992;7:743-9.

88. Porter PL, Gown AM, Kramp SG, Coltrera MD. Wide-spread p53 overexpression in human malignant tumors: an immunohistochemical study using methacarn-fixed, embedded tissue. Am J Pathol 1992;140:145-53. 
89. Kishimoto Y, Murakami Y, Shiraishi M, Hayashi K, Sekiya T. Aberrations of the $p 53$ tumor suppressor gene in human non-small cell carcinomas of the lung. Cancer Res 1992;52: 4799-804.

90. Westra WH, Offerhaus JA, Goodman SN, Slebos RJC, Polak $\mathrm{M}$, Baas IO, et al. Overexpression of the p53 tumor suppressor gene product in primary lung adenocarcinomas is associated with cigarette smoking. Am J Surg Pathol 1993;17:21320.

91. Brambilla E, Gazzeri S, Moro D, Fromentel CC, Gouyer V, Jacrot M, et al. Immunohistochemical study of p53 in human lung carcinomas. Am J Pathol 1993;143:199-210.

92. Cagle PT, Fraire AE, Greenberg SD, Cox A, Brown RW. Potential utility of p53 immunopositivity in differentiation of adenocarcinomas from reactive epithelial atypias of the lung. Hum Pathol 1996;27:1198-203.

93. Sundaresan V, Ganly P, Hasleton P, Rudd R, Sinha G, Bleehen NM, et al. p53 and chromosome 3 abnormalities characteristic of malignant lung tumours are detectable in preinvasive lesions of the bronchus. Oncogene 1992;7:1989-97.

94. Sozzi G, Miozzo M, Donghi R, Pilotti S, Cariani CT, Pastorino $\mathrm{U}$, et al. Deletions of 17p and p53 mutations in preneoplastic lesions of the lung. Cancer Res 1992;52:6079-82.

95. Nuorva K, Soini Y, Kamel D, Autio-Harmainen H, Risteli L, Risteli J, et al. Concurrent p53 expression in bronchial dysplasias and squamous cell lung carcinomas. Am J Pathol 1993;142:725-32.

96. Bennett WP, Colby TV, Travis WD, Borkowski A, Jones RT, Lane DP, et al. p53 protein accumulates frequently in early bronchial neoplasia. Cancer Res 1993;53:4817-22.

97. Hirano T, Franzén B, Kato H, Ebihara Y, Auer G. Genesis of squamous cell lung carcinoma: sequential changes of proliferation, DNA ploidy, and p53 expression. Am J Pathol 1994;144:296-302.

98. Hayashi H, Miyamoto H, Ito T. Analysis of p21 Waf/Cip expression in normal, premalignant and malignant cells during the development of human lung adenocarcinoma. Am J Pathol 1997;151:461-70.

99. Slebos RJC, Baas IO, Clement MJ, Offerhouse GJ, Askin FB, Hruban RH, et al. p53 alterations in atypical alveolar hyperplasia of the human lung. Hum Pathol 1998;29:801-8.

100. Tateishi M, Ishida T, Mitsudomi T. Prognostic value of c-erbB-2 protein expression in human lung adenocarcinoma and squamous cell carcinoma. Eur J Cancer 1991;27: 1372-5

101. Pääkkö P, Nuorva K, Kamel D. Evidence by in situ hybridization that c-erbB-2 proto-oncogene expression is a marker of malignancy and is expressed in lung adenocarcinomas. Am J Respir Cell Mol Biol 1992;7:325-34.

102. Yashima K, Litzky LA, Kaiser L. Telomerase expression in respiratory epithelium during the multistage pathogenesis of lung carcinomas. Cancer Res 1997;57:2373-7.

103. Boorman GA, Eustis SL, Elwell MR, Montgomery CA, Mackenzie WF, editors. Pathology of the Fischer rat: reference and atlas. San Diego: Academic Press; 1990.

104. Reznik-Schuller HM, Resnik G. Morphology of spontaneous and induced tumors in the bronchiolo-alveolar region of Fischer 344 rats. Anticancer Res 1982;2:53-8.

105. Spencer H. Pathology of the lung. Vol 2. 4th ed. New York: Pergamon Press; 1985.

106. Cubo-Caparo A, De La Vega E, Copaira M. Pulmonary adenomatosis of sheep-metastasizing bronchiolar tumors. Am J Vet Res 1961;22:673-82.

107. Enchev S. On, the question of malignant forms of the socalled pulmonary adenomatosis in sheep. Neoplasma (Bratislava) 1963;10:291-303.

108. Nobel TA, Perk K. Animal model of human disease. Bronchiolar alveolar cell carcinoma. Animal model: pulmonary adenomatosis of sheep (Jaagsietke). Am J Pathol 1978;90: 783-6.

109. Rosadio RH, Sharp JM, Lairore MD. Lesions and retroviruses associated with naturally occurring ovine pulmonary carcinoma (sheep pulmonary adenomatosis). Vet Pathol 1988;25:58-66.

110. Demartini JC, Rosadio RH, Lairmore MD. The etiology and pathogenesis of ovine pulmonary carcinoma (sheep pulmonary adenomatosis). Vet Microbiol 1988;17:219-36.

111. Hecht SJ, Sharp JM, Demartin JC. Retroviral etiopathogenesis of ovine pulmonary carcinoma: a critical appraisal [comment]. Br Vet J 1996;152:395-9.

112. Travis WD, Colby TV, Corrin B, Shimosato Y, Brambilla E, editors. Histological typing of lung and pleural tumors. World Health Organization international classification of tumours. 3rd ed. Berlin: Springer; 1999.

113. Sone S, Takashima S, Li F, Yang Z, Honda T, Maruyama Y, et al. Mass screening for lung cancer with mobile spiral computed tomography scanner. Lancet 1998;351:1242-5.

114. Colby TV, Wistuba II, Gazdar A. Precursors to pulmonary neoplasia [review]. Adv Anat Pathol 1998;5:205-15.

115. Ritter JH. Pulmonary atypical adenomatous hyperplasia: a histologic lesion in search of usable criteria and clinical significance [editorial]. Am J Clin Pathol 1999;111:587-9. 